\title{
IMPLANTAÇÃO DO BUILDING INFORMATION MODELING AOS PROJETOS DE ENGENHARIA DO SISTEMA FEDERAL BRASILEIRO
}

\section{ARTIGO ORIGINAL}

COAN, Débora Regina Thomaz do Nascimento ${ }^{1}$, SOUZA, Normelio Junior de ${ }^{2}$, QUEIROZ, Altamira de Souza ${ }^{3}$

COAN, Débora Regina Thomaz do Nascimento. SOUZA, Normelio Junior de. QUEIROZ, Altamira de Souza. Implantação do Building Information Modeling aos projetos de engenharia do sistema federal Brasileiro. Revista Científica Multidisciplinar Núcleo do Conhecimento. Ano. 06, Ed. 12, Vol. 01, pp. 84-110. Dezembro de 2021. ISSN: 2448-0959, Link de acesso: https://www.nucleodoconhecimento.com.br/engenharia-civil/projetos-de-engenharia, DOI: 10.32749/nucleodoconhecimento.com.br/engenharia-civil/projetos-deengenharia

\section{RESUMO}

O presente artigo descreve a estratégia do Sistema Federal Brasileiro, para a propagação e implantação da tecnologia Building Information Modeling (BIM), para os projetos de engenharia das obras públicas diretas e indiretas até o ano de 2028. Neste contexto, o presente artigo, tem como questão norteadora: Como será realizada a implantação do Building Information Modeling para elaboração dos projetos de engenharia do Sistema Federal Brasileiro? O objetivo geral da pesquisa é fazer um levantamento sobre a implantação da tecnologia BIM para execução de projetos de engenharia do Sistema Público Federal Brasileiro e seus impactos. Através de pesquisas bibliográficas sobre o tema tratado, estuda-se o surgimento da tecnologia $B I M$, o processo de implantação no Brasil e as etapas da estratégia BIMBR para a solidificação da tecnologia. Mediante pesquisa bibliográfica, realiza-se

\footnotetext{
${ }^{1}$ Graduação em Engenharia Civil. ORCID: 0000-0001-7450-7849.

${ }^{2}$ Graduação em Engenharia Civil. ORCID: 0000-0002-5998-971X.

${ }^{3}$ Orientador. ORCID: 2789925412042209.
} 
a comparação de um projeto de moradia popular, através da modelagem tridimensional, usando-se a tecnologia BIM e o programa Cad, desse modo, comprova-se a economia de $11 \%$ no orçamento total da obra, a diminuição de 5 horas de trabalho no processo de modelagem e a redução de 4 horas no preenchimento da planilha de prestação de contas para o financiamento do projeto de moradia, disponibilizada pela Caixa Econômica Federal.

Palavras-chave: Tecnologia BIM, Projetos públicos, Disseminação, Orçamento, Softwares.

\section{INTRODUÇÃO}

A tecnologia BIM (Building Information Modeling) representa para Thomé (2016), o desenvolvimento de projetos modelados no plano 3D, para conteúdos volumétricos e parametrizados onde é possível perceber toda a característica de um processo construtivo, desde os materiais utilizados até suas marcas e precificações, permitindo a integração de diversas áreas de projetos de engenharia. A discussão de seu uso no Brasil é dada a partir do ano de 2000, onde anteriormente a tecnologia predominante era o programa Cad (Computer Aided Design), o qual era utilizado para realização dos projetos, arquitetônicos, executivos, estruturais, de instalações hidráulicas e elétricas.

Neste contexto, o presente artigo tem como questão norteadora: Como será realizada a implantação do Building Information Modeling para elaboração dos projetos de engenharia do Sistema Federal Brasileiro?

É evidente que, com a implantação da tecnologia, os investimentos para moradias de baixa renda serão mais bem aproveitados e a capacitação em BIM será expandida. A falta de conhecimento técnico da BIM é um problema enfrentado pelas engenharias dos órgãos públicos, na elaboração de projetos.

Para Thomé (2016), BIM é uma nova maneira de integrar e organizar dados, elementos e materiais de uma construção do início ao fim, permitindo o 
compartilhamento simultâneo das informações do projeto por diferentes profissionais.

A modelagem com o programa $\mathrm{Cad}$, apresenta alguns obstáculos, como por exemplo, um projeto de instalações pode entrar em conflito com o projeto estrutural, arquitetônico e hidrossanitário. Com o objetivo de solucionar tais conflitos e otimizar o processo de gestão de dados digitais, foi desenvolvida a tecnologia BIM.

Thomé (2016), afirma que a tecnologia $B I M$ pode minimizar divergências encontradas em projetos bidimensionais, devido a modelagem ser totalmente realizada no campo tridimensional, o que detalha a interação feita por cada objeto do desenho.

A tecnologia BIM, impulsiona a modernização na Construção Civil e traz consigo melhoria para os processos construtivos e administrativos, na qual incorpora-se aquilo que existe de fato, para o desenvolvimento e planejamento de todas as etapas da construção.

Através dessa sequência de processos baseados em um modelo de edificação digital, oferece-se compatibilização e parametrização de projetos, antecipando erros na jornada e evitando gastos inesperados.

A propagação da tecnologia BIM para o Sistema Federal Brasileiro, é a grande estratégia da ABDI - Agência Brasileira de Desenvolvimento Industrial, que possui dois objetivos bem claros: treinar BIM no setor privado e desenvolver cenários e bibliotecas adequados para disponibilizar objetos BIM, estimulando cada vez mais os usuários comuns e fabricantes. (ABDI, 2019).

O Governo Federal vem atualizando leis e projetos para tornar obrigatório o emprego de BIM no desenvolvimento de projetos de engenharia do setor público, com isso, as obras do programa Casa Verde e Amarela, tendem a ser totalmente desenvolvidos em BIM. Previsto para ser totalmente implantado no ano de 2028, há a possibilidade de a nova regra efetivar-se no ano de 2022, proporcionando 
incentivo na redução dos gastos para a execução de casas populares (CHEBATT, 2021).

Além da implantação da regulamentação da tecnologia BIM nos projetos de Engenharia e Arquitetura para órgãos públicos, evidencia-se que com a chegada da tecnologia, diversos erros retratados nos projetos, poderão ser minimizados já em sua concepção e com o decreto, muitas empresas públicas e privadas aumentarão sua produtividade, colaborando para o crescimento do Produto Interno Bruto da Construção Civil do Brasil.

Sabe-se que é possível fazer uso da tecnologia BIM para a geração, compatibilização e parametrização dos projetos públicos de engenharia, neste sentido, justifica-se a iniciativa do governo, desempenhada de maneira escalonada, a fim de oferecer tempo de adaptação ao mercado e ao setor público.

Espera-se mostrar, através dessa pesquisa, os benefícios financeiros gerados para a elaboração de uma moradia popular, ao manipular ferramentas que interagem com a BIM, quando ao ser comparada com programas similares de desenvolvimento de projetos de engenharia e mostrar a evolução do sistema de modelagem. Assim como, apontar a importância da modernização e virtualização para os processos construtivos.

O objetivo geral da pesquisa é fazer um levantamento sobre a implantação da tecnologia BIM para execução de projetos de engenharia do Sistema Público Federal Brasileiro e seus impactos. Os objetivos específicos do trabalho são:

- Fazer um estudo bibliográfico sobre BIM;

- Comparar o sistema Cad com BIM e estudar os impactos financeiros;

- Apresentar os benefícios da utilização de BIM para elaboração de projetos de construção;

- Mostrar o Produto Interno Bruto - (PIB) Total do Brasil e avaliar o PIB da Construção Civil dos últimos cinco anos; 
- Fazer um levantamento dos softwares utilizados para a parametrização em BIM e seus custos;

- Apresentar o plano do Governo Federal, BIMBR;

- Levantar opiniões de autores, arquitetos, engenheiros e construtoras sobre o uso em BIM;

- Comparar BIM com ferramentas genéricas.

Para a elaboração do trabalho, foi necessário um levantamento bibliográfico, verificando autores que realizaram comparações de sistemas similares à BIM.

A busca por fontes bibliográficas foi realizada através de livros disponíveis na biblioteca, artigos científicos e trabalhos à disposição em plataformas de dissertações acadêmicas, além de acesso às organizações do governo que referenciam o assunto.

\section{DESENVOLVIMENTO}

\section{O SURGIMENTO DA BIM}

A tecnologia BIM, nasceu pela necessidade de um projeto conter informações indispensáveis sobre as características, fase de obra, lista de materiais e processos construtivos, abrindo portas para uma nova maneira de projetar, passando de projetos e documentos elaborados em papel, para o emprego de sistemas computacionais.

Apresentado por Eastman em 1986 no então AlA Journal, o mais antigo exemplo do conceito do que se conhece hoje como BIM foi o protótipo BDS "Building Description System" na tradução, Sistema de Descrição de Construção, considerado precursor da tecnologia. Com a evolução dessa nomenclatura, em dezembro 1992, F. Tolman utilizou-se da terminologia "Building Information Modeling" em um artigo no Automation in Construction e assim tem circulado (COSTA et al., 2017). 
Para Figuerola (2011, p. 58-60), conforme citado por Menezes (2011, p. 153), um dos pioneiros no uso BIM, Christiano Ceccato, juntamente com o norte-americano Frank Gehry, ajudou a fundar no ano de 2002, a Gehry Technologies, empresa voltada aos serviços de modelagem BIM.

A ideia não é muito recente, desde os anos 80 já existiam softwares capazes de produzir uma modelagem 3D com informações agregadas, porém somente no início do século 21 tornaram-se mais populares. Para Costa et al. (2017), as condições de difusão se estabeleceram a partir do ano de 2005, quando foi publicada a ISO-PAS 16739-2005, Industry Foundation Classes, Release 2x, Platform Specification (IFC2x Platform) seguida pela versão IFC2x em 2007, que consiste no padrão de configuração de dados aberto e neutro, definido pela Norma ISO 16739:2013 e que pode ser considerada como a referência básica em BIM tal como está estruturado hoje.

Para Thórus (2020), a adoção da tecnologia BIM desenvolve-se mais com o passar dos anos e ao agregar inúmeras proporções para o projeto, expõe-se processos construtivos baseado em diferentes dimensões, que envolvem do 3 ao $8 \mathrm{D}$, dependendo da complexidade do projeto.

Em BIM 3D, obtém-se a modelagem tridimensional de informações técnicas, tamanho e localização espacial, possibilitando a detecção de conflitos e a extração da lista de materiais utilizadas ao longo da construção. Na dimensão 4D, adiciona-se o parâmetro "tempo" para inspecionar a evolução da obra de forma virtual; em BIM $5 \mathrm{D}$, integram-se os elementos associados às características orçamentárias do projeto que são frequentemente atualizados (THÓRUS, 2020).

Do mesmo modo, Thórus (2020), ainda explica que a dimensão 6D, abrange o conforto térmico e simulações como temperatura, energia e iluminação arquitetônica; BIM 7D trata-se do pós-obra, parâmetros para manutenção, garantia e funcionamento do projeto e, por fim, fala-se em BIM 8D, segurança do trabalho, responsável por antecipar qualquer risco na realização da obra. 


\section{IMPLANTAÇÃO NO BRASIL}

No Brasil, a partir do ano de 2000, iniciou-se uma discussão para a implementação da BIM. Para a inserção desta tecnologia, foi criada a Lei de número 14.133/21, que estabelece no seu artigo 19, parágrafo 3 , a preferência do emprego da tecnologia BIM nas documentações para a regularização e autorização na participação de licitações em qualquer nova obra de engenharia ou arquitetura (BRASIL, 2021).

A INBEC (2020), retrata a ordem para a implementação da BIM no Brasil, expondo que, a partir de janeiro de 2021, a tecnologia BIM será usada para projetar modelos para arquitetura e engenharia em disciplinas como estrutura, hidráulica, AVAC (sistemas de aquecimento, ventilação e ar-condicionado) e elétrica para detectar interferências, extrair quantitativos e gerar documentos gráficos. A partir de janeiro de 2024 deve-se incluir a execução da obra planejada, orçamento e atualizações, como as built, bem como a primeira fase exigida e, a partir de janeiro de 2028 ao considerar os serviços de gestão e manutenção, todo o período de vida da obra será coberto e aplicado, pelo menos, em novas construções, reformas, ampliações ou restaurações, quando consideradas de moderada ou significativa relevância, seguindo as utilizações previstas na primeira e segunda fases.

Para Rocha (2011, p. 38-43, apud MENEZES, 2011, p. 153), a tecnologia BIM possibilitará uma mudança considerável na produção da construção civil, porém pela ideia ser tão tecnológica e revolucionária, o conceito da modelagem estaria longe de ser adotado no Brasil, apesar das dificuldades de implantação, essa plataforma já começou a ser utilizada por vários profissionais das áreas de engenharia, orçamentos, arquitetura, estruturas, instalações prediais e de vedação.

Atualmente, um dos principais gargalos no campo de atuação da construção civil brasileira, diz respeito à falta de qualidade dos projetos, o qual está relacionado a outro grave fator: o longo ciclo temporal para realização de obras no país. A maioria desses problemas provém de projetos inadequados, tanto de edificações como de infraestrutura, dessa forma, o conjunto de fases operacionais da construção, 
necessita incorporar tecnologias e processos mais eficazes na sua atividade, objetivando ampliar a qualidade de seus projetos aprimorando sua produtividade.

A Norma ABNT NBR 15965-1:2011, que está sendo desenvolvida, define a terminologia, os princípios do sistema de classificação e os grupos de classificação para o planejamento, projeto, gerenciamento, obra, operação e manutenção de empreendimentos da construção civil (ABNT, 2011).

A Norma ABNT NBR ISO 12006-2:2018, estabelece uma estrutura para o aprimoramento de sistemas de classificação do ambiente construído. Ela identifica um grupo de títulos de tabelas de classificação, recomendadas para uma variedade de classes de objetos da construção, de acordo com pontos de vista diversos e particulares, por exemplo, pela forma ou pela função (ABNT, 2018).

O mais comum no Brasil é se trabalhar até a dimensão $5 \mathrm{D}$, pois abrange os processos de projeto, planejamento e orçamento, porém a necessidade em atender as normas de desempenho, considera-se simulações contempladas no plano 6D.

É de grande importância ressaltar os avanços da tecnologia BIM ao longo dos anos no Brasil, na Figura 1 pode-se observar que em 2014 foi lançado o Guia de Boas Práticas em BIM, somente após dois anos foi criado uma coletânea de Implementação BIM para Construtoras e Incorporadoras da CBIC - Câmera Brasileira de Indústria e Construção. Ainda em 2016 um acordo de cooperação entre o Brasil e o Reino Unido para uso BIM no poder público marcou a realização dessa tecnologia no Brasil. Em 2019, a criação de um decreto de disseminação BIM e a criação do Comitê Gestor de Estratégia BIM fortaleceram a utilização dessa tecnologia a ponto de, em 2020 acontecer o lançamento do BIM Fórum Brasil. 
Figura 1: Marcos em BIM no Brasil

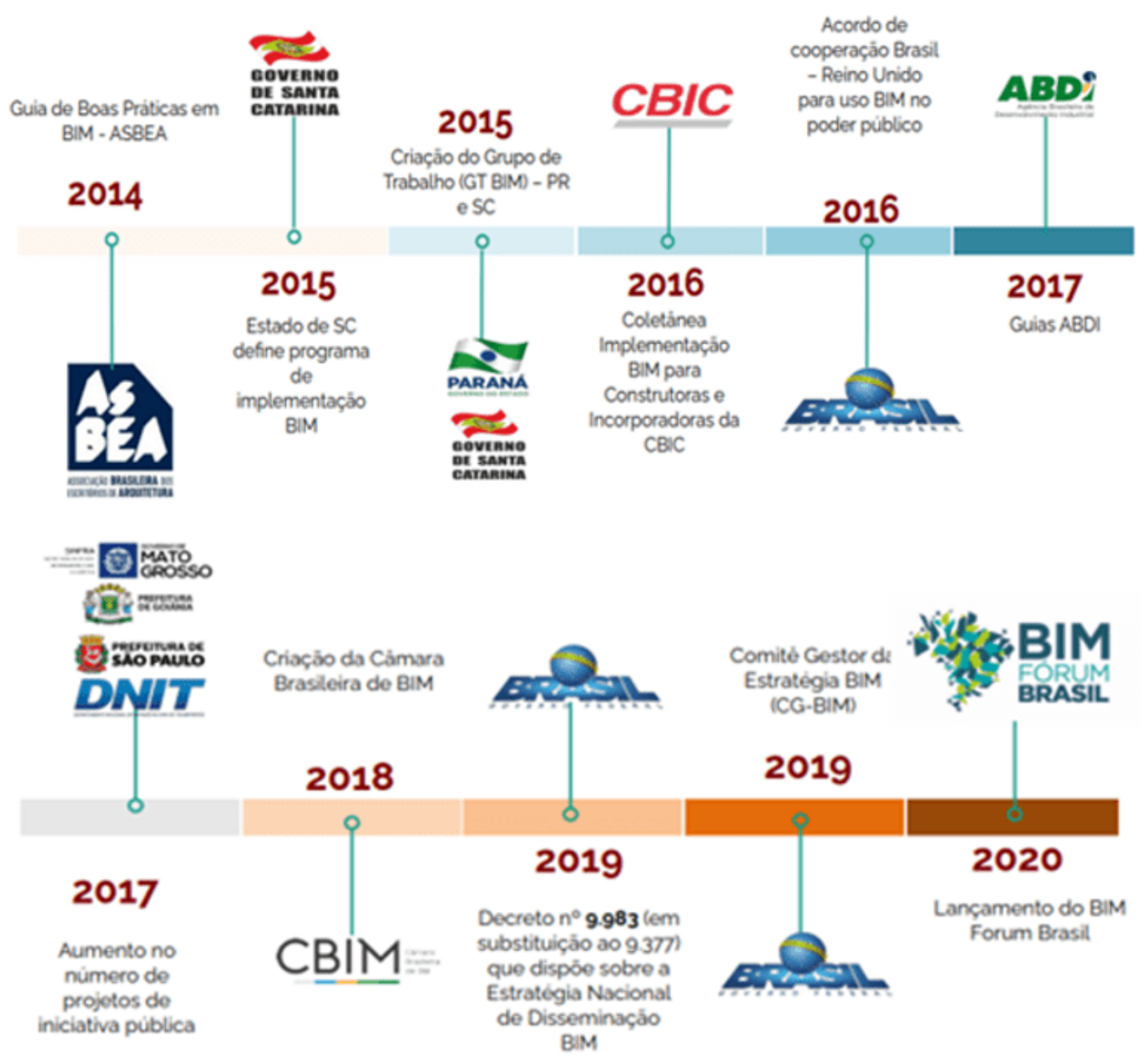

Fonte: Holsback, 2019. Qualidade e desenvolvimento dos Projetos.

\section{PLANO DE ESTRATÉGIA BIM BR}

A tecnologia BIM está inserida na Agenda Estratégica do Plano Brasil Maior (PBM), como uma das prioridades da política do Governo Federal ao Setor da Construção Civil. O Plano Brasil Maior, lançado em 02 de agosto de 2011, é um programa do Governo Federal Brasileiro com o intuito de expandir a competitividade da indústria nacional, sob o lema: "Inovar para competir, competir para Crescer" (BAIA, 2015).

RC: 102547

Disponível em: https://www.nucleodoconhecimento.com.br/engenharia-civil/projetosde-engenharia 
Segundo Baia (2015), a pauta trata-se de idealizar uma nova política industrial, tecnológica, de serviços e de comércio exterior agregadas ao governo federal.

O Decreto de número 10.306, de 02 de abril de 2020, estabelece que:

A utilização do $B I M$ na execução direta ou indireta de obras e serviços de engenharia realizada pelos órgãos e pelas entidades da administração pública federal, no âmbito da Estratégia Nacional de Disseminação do BIM - Estratégia BIMBR, instituída pelo Decreto no 9.983, de 22 de agosto de 2019, Art. 1o Este Decreto estabelece a utilização do Building Information Modelling - BIM ou Modelagem da Informação da Construção na execução direta ou indireta de obras e serviços de engenharia, realizada pelos órgãos e pelas entidades da administração pública federal, no âmbito da Estratégia Nacional de Disseminação do BIM - Estratégia BIMBR, instituída pelo Decreto no 9.983, de 22 de agosto de 2019. (BRASIL, 2020, p. $5)$.

Baia (2015), ao destacar a consolidação em BIM na Europa, USA e Ásia como preferência no desenvolvimento de projetos e nos aplicativos voltados à gestão e controle de obra, observa a grande importância do tema para se obter a modernização e industrialização da Construção no Brasil.

ABDI (2019) afirma que, pretendendo ampliar a sinergia entre os vários agentes envolvidos e acelerar o processo de implantação e difusão em BIM no Brasil, o Ministério de Desenvolvimento, Indústria e Comércio Exterior, MDIC e a Agência Brasileira de Desenvolvimento Industrial (ABDI), vêm articulando e formalizando parcerias com agentes estratégicos.

Nesse contexto, já foram estabelecidos acordos e convênios com a ABNT e o Exército Brasileiro. Vale ressaltar que no ano de 2020, a ABDI lançou o curso básico "Democratizando o $B I M$ ', totalmente online e gratuito, com o intuito de contextualizar os fundamentos históricos e normativos da plataforma ABDI (2019).

O Ministério da Indústria, Comércio Exterior e Serviços estabelece a elaboração de processos por etapas a fim de acumular resultados positivos ao longo dos anos. 
Observa-se na Figura 2, que o início da Estratégia BIMBR, proporcionou no ano de 2018 a criação da Governança em BIM, que tem como objetivo ter as atividades de popularização da tecnologia em pleno funcionamento até o ano de 2028. Para isso, conta-se com 0 desenvolvimento gradativo de estruturação em compras governamentais em vigor desde 2018, onde estima-se que até o ano de 2028 toda a estrutura legal e infralegal esteja aperfeiçoada, assim como a propagação BIM em todo projeto de obras públicas motivada pelo Governo Federal. Com base nos dados, a medida para essa estratégia garante que até 2028, o PIB da Construção Civil tenha um acréscimo de $28,9 \%$.

Figura 2: Mapa da Estratégia BIMBR

\begin{tabular}{|c|c|c|c|c|}
\hline Resultados & $\begin{array}{l}\text { Aumentar a produtividade } \\
\text { das empresas em } 10 \%\end{array}$ & Reduzir custos em 9,7\% & $\begin{array}{l}\text { Aumentar em 10xa adoç\$0 } \\
\text { do Bum (\% do piB da } \\
\text { construçäo civil) }\end{array}$ & $\begin{array}{l}\text { Elevar em 28,9\%० } \\
\text { PiB da construçăo } \\
\text { civil }\end{array}$ \\
\hline \multicolumn{5}{|c|}{2024} \\
\hline Governança & $\begin{array}{l}\text { Estabelecer } \\
\text { instíncia de } \\
\text { gestio }\end{array}$ & $\begin{array}{l}\text { Cerenciar as atividades da Estratc } \\
\text { Analisar e publicar resultados }\end{array}$ & BIM BR/ & $\begin{array}{l}\text { Estratigia Bim Be } \\
\text { implantadae } \\
\text { metas atingidas }\end{array}$ \\
\hline $\begin{array}{l}\text { Infraestrutura } \\
\text { Tecnológica e } \\
\text { Inovaçäo }\end{array}$ & \multicolumn{3}{|c|}{ 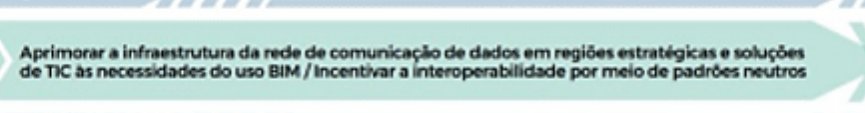 } & $\begin{array}{l}\text { Incentivo } \\
\text { continuado ao } \\
\text { deservoluimento } \\
\text { tecrolidgico }\end{array}$ \\
\hline $\begin{array}{l}\text { Arcabouço } \\
\text { Legal }\end{array}$ & $\begin{array}{l}\text { Estabelecer os } \\
\text { requilitos BiM para } \\
\text { compras } \\
\text { gowimamentals }\end{array}$ & \multicolumn{2}{|c|}{$\begin{array}{l}\text { Aprimorar o marco legal e infralegal referente as } \\
\text { compras publicas para o uso extensivo do BIM }\end{array}$} & $\begin{array}{l}\text { Arcabouco legal e } \\
\text { infralogal } \\
\text { aperfeicasdo }\end{array}$ \\
\hline $\begin{array}{l}\text { Regulamentação } \\
\text { Técnica }\end{array}$ & $\begin{array}{l}\text { Estabelecer documentose } \\
\text { referencias tecnicas para } \\
\text { edificasbes e infraestrutura }\end{array}$ & \multicolumn{2}{|c|}{ 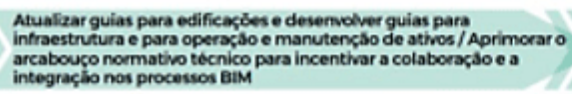 } & $\begin{array}{l}\text { Regulamentachio } \\
\text { tecnica apeimorads }\end{array}$ \\
\hline Investimentos & \multicolumn{3}{|c|}{ Promover ambiente de negocio favordvel a atraçaso de imvestimentos em BIM } & $\begin{array}{l}\text { Irvestimentos em } \\
\text { Eim efetivados }\end{array}$ \\
\hline Capacitação & $\begin{array}{l}\text { Estatelecer objetivos de } \\
\text { sprendizagem/Eloborar } \\
\text { disciplinss modelo }\end{array}$ & \multicolumn{2}{|c|}{ 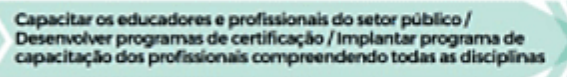 } & $\begin{array}{l}\text { Atualizecaloe } \\
\text { educasdo } \\
\text { continuads }\end{array}$ \\
\hline $\begin{array}{l}\text { Indução pelo } \\
\text { Governo Federal }\end{array}$ & $\begin{array}{l}\text { Estruturar o Covemo para } \\
\text { adocäo do BiM nos } \\
\text { Programas Piloto (DNIT, } \\
\text { SAC, MB e EB) }\end{array}$ & $\begin{array}{l}\text { Adotar BaM em projetos dos } \\
\text { Programas Piloto }\end{array}$ & $\begin{array}{l}\text { Adotar aim em projetose } \\
\text { obras e incluir novios } \\
\text { programas }\end{array}$ & $\begin{array}{l}\text { Bam disseminado } \\
\text { em obras públicas }\end{array}$ \\
\hline Comunicação & \multicolumn{3}{|c|}{$\begin{array}{l}\text { Difundir o conceito BIM e seus beneficios / Divulgar a Estrategia BIM BR e seus resultados / } \\
\text { Promover a Plataforma e a Biblioteca Nacianal Bim }\end{array}$} & $\begin{array}{l}\text { Atores } \\
\text { mobilizados }\end{array}$ \\
\hline
\end{tabular}

Fonte: MDIC: Ministério da Indústria, Comércio Exterior e Serviços.

RC: 102547

Disponível em: https://www.nucleodoconhecimento.com.br/engenharia-civil/projetosde-engenharia 


\section{COMPARATIVOS ORÇAMENTÁRIOS DA CONSTRUÇÃO CIVIL}

A tecnologia BIM tem fomentado a mudança do bidimensional para o tridimensional.

É no cronograma de obras, ou sequenciamento de atividades que encontra-se hoje, o principal uso de BIM associado ao planejamento de obras permitindo o estudo da logística do canteiro e, com o processo facilitado de compatibilização quando trabalha-se em BIM, evidencia-se que a assertividade dos quantitativos cresce muito e mitiga os erros recorrentes de compras em obra, e precisão de custo. (SIENGE, 2021).

A construção civil, ainda destacada por Sienge (2021), é considerada como um dos serviços que menos se pratica a ousadia de mercado e que a inovação para a indústria no Brasil, por exemplo, equivale a $35,7 \%$ do PIB total, ainda ressalta que $29,6 \%$ é o índice relativo à construção civil, dado que representa apenas $8 \%$ do PIB nacional, ou seja, esse percentual ainda é considerado ineficaz na promoção de renda por meio da integração da tecnologia.

Ao expressar os dados financeiros do país, nota-se na Figura 3, a diminuição do PIB Total nos dois primeiros trimestres de 2020, muito se deve ao fato da Covid-19 ter elevado o número de casos e mortos no país. Para CBIC (2021), mesmo diante da chegada da $2^{\mathrm{a}}$ onda no final do ano de 2020 , percebe-se um crescimento consistente do desempenho no país no setor da Construção. 
Figura 3: PIB Brasil - Variação trimestral imediatamente anterior com ajuste sazonal 2017 a 2021

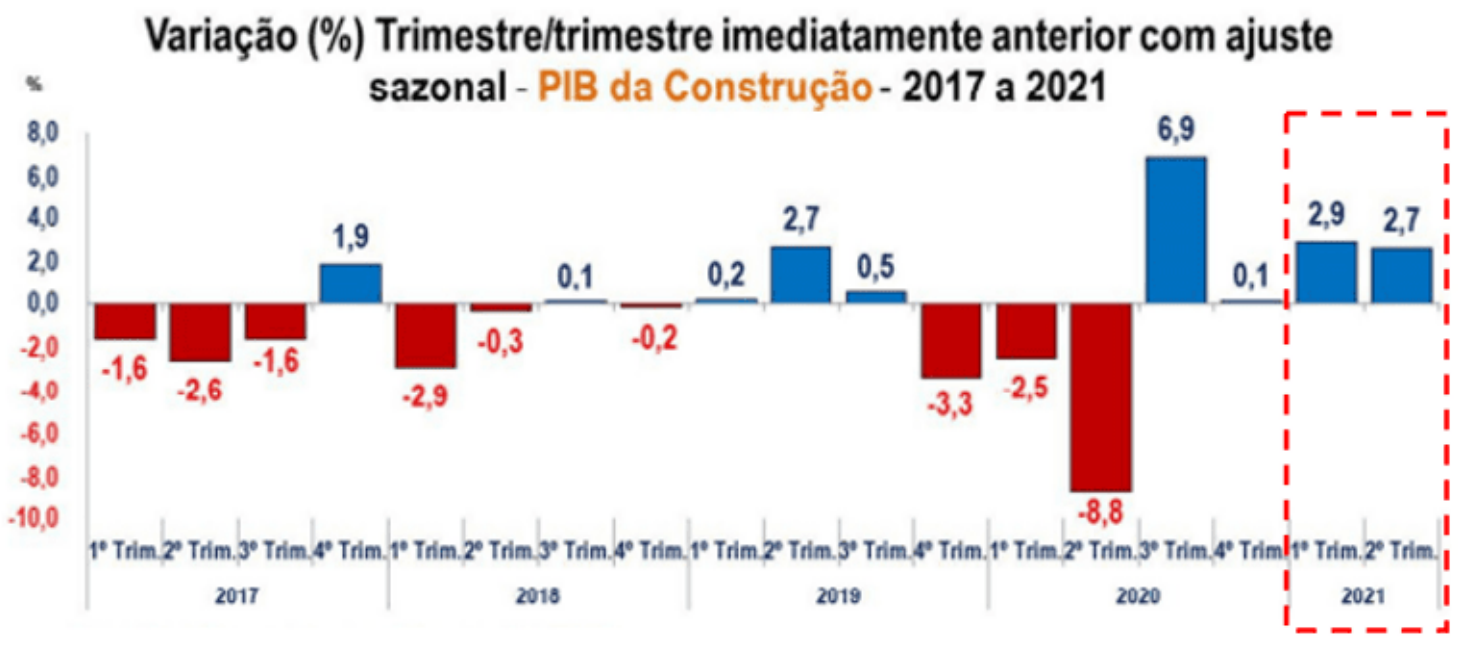

Fonte: Contas Nacionais Trimestrais - $2^{\circ}$ Trimestre de 2021, IBGE.

Pelo quinto ano consecutivo o ramo da construção civil, tem um encolhimento na variação do PIB. Segundo CBIC (2021), a construção encolheu 2,5\% em 2018, acumulando retração de $27,7 \%$ neste período. Houve também redução da participação do setor, no investimento de $52 \%$ para $47 \%$, no PIB nacional de $4,8 \%$ para $4,5 \%$ e na indústria de $22,4 \%$ para $20,6 \%$.

De maneira geral, ao analisar a variação econômica por setor de atividade, percebese na Figura 4, a evolução da Construção Civil em 2,7\% em relação aos outros setores nos dois primeiros trimestres do ano de 2021, o que levou a superar a alta do PIB Nacional que foi de $1,8 \%$. 
Figura 4: Variação do PIB no 2ำ trimestre por setor de atividade econômica - 2021

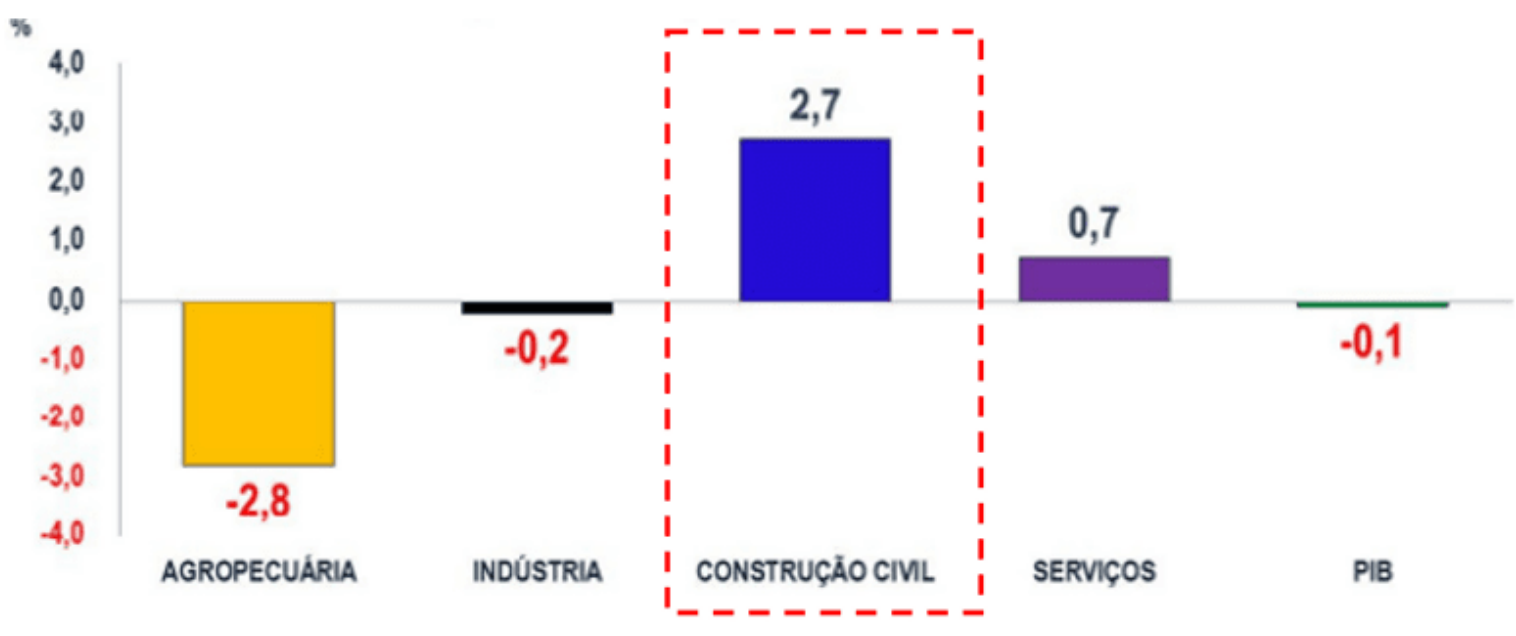

Fonte: Contas Nacionais Trimestrais - 2º Trimestre de 2021, IBGE.

CBIC (2019), avalia que daqui para frente, a previsão é de aceleração lenta e gradual da atividade, com juros e inflação baixos e ociosidade na economia.

Baseando-se nos dados apresentados na Figura 5, os números atuais, caso a construção cresça a taxas de 1\% ao ano, somente em 2050 a área voltará ao patamar de 2014; a taxas de $2 \%$ ao ano, somente em 2035 e a taxas de $4 \%$ ao ano somente em 2026. "O encolhimento do setor foi muito intenso e profundo e o cenário ainda é preocupante, isso se deve principalmente, à perda de dinamismo do setor da construção nos últimos anos" (CBIC, 2019). 
Figura 5: PIB da Construção

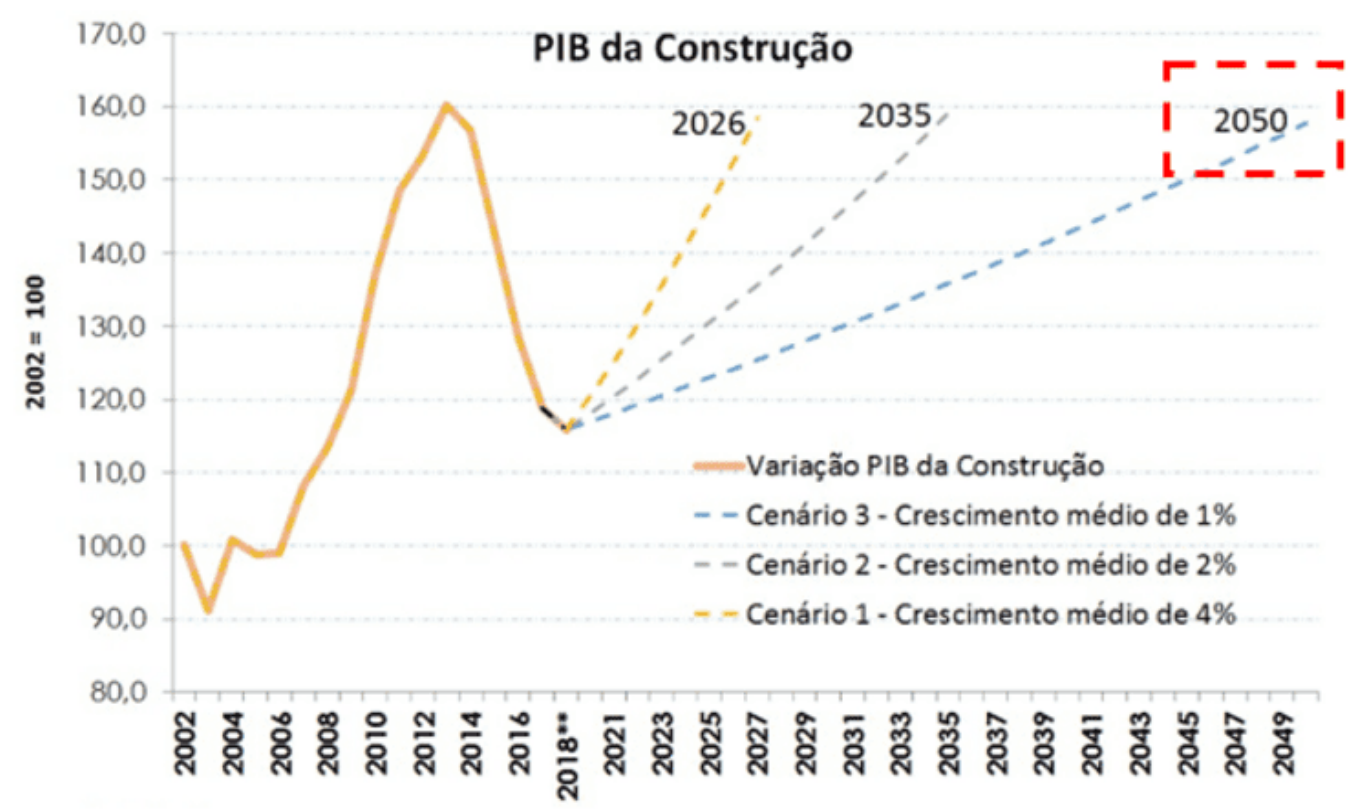

Nota $^{* \star}$ Contas nacionais trimestrais acumulada 4 trimestres de 2018, projeção CBIC. Fonte: IBGE, 2018.Estima-se que, à medida que a categoria da construção progrida gradativamente, a busca pela construção virtualizada é um dos grandes desafios para estimular o crescimento do mercado da construção e uma estratégia para minimizar as variações negativas pelo qual o segmento tem passado nos últimos anos. Ou seja, quanto maior o crescimento menor seu tempo para evolução.

Observa-se que o cenário a médio e longo prazo se mostra positivo, conforme CBIC (2019) avalia, as licenças, o padrão legislativo de saneamento, a necessidade de infraestrutura logística e a demanda por moradias, reforçam as expectativas para o crescimento do setor.

\section{A RELAÇÃO BIM X AUTOCAD}

Estudos concluíram que em BIM pode-se reduzir duas vezes o tempo de criação de produtos de engenharia em infraestrutura, cita ainda que uma única pessoa, com conhecimento prévio do sistema, consegue obter um rol de informações maior do 
que um grupo de pessoas que elaboram um mesmo projeto através do método tradicional. (COBENGE, 2012).

A tecnologia BIM pode diminuir os custos diretos de engenharia, devido a redução do tempo de equipes, a produção quase totalmente automatizada, a formação de desenhos paramétricos, os levantamentos quantitativos, o retrabalho e a coordenação eficaz do empreendimento (EASTMAN et al., 2014).

Conforme o fluxo da execução de uma edificação vai terminando, os custos tendem a aumentar exponencialmente e diminuir da mesma maneira à capacidade das mudanças, em BIM, a integração de atributos, faz com que o anteprojeto seja tão completo quanto o projeto final. Devido a anexação de todos os dados, é viável a alteração de melhorias, antes do início da execução do empreendimento implicando em menor custo para o proprietário (EASTMAN et al., 2014).

Através do estudo desenvolvido por Nunes; Leão (2018, p. 47), para a execução do projeto de uma residência pelo sistema público Casa Verde e Amarela, avalia-se a sequência executiva através da manipulação em BIM. A Figura 6 , apresenta o tempo por disciplina acumulado, necessário para a construção do projeto, através dos sistemas AutoCad e BIM, nota-se que a maior diferença de prazo em benefício BIM, consiste na elaboração do projeto arquitetônico e no cronograma físico financeiro, entretanto para os processos estruturais e elétricos, os resultados mostram-se desfavoráveis. 
Figura 6 - Comparativo horário de desenvolvimento de processos e projetos.

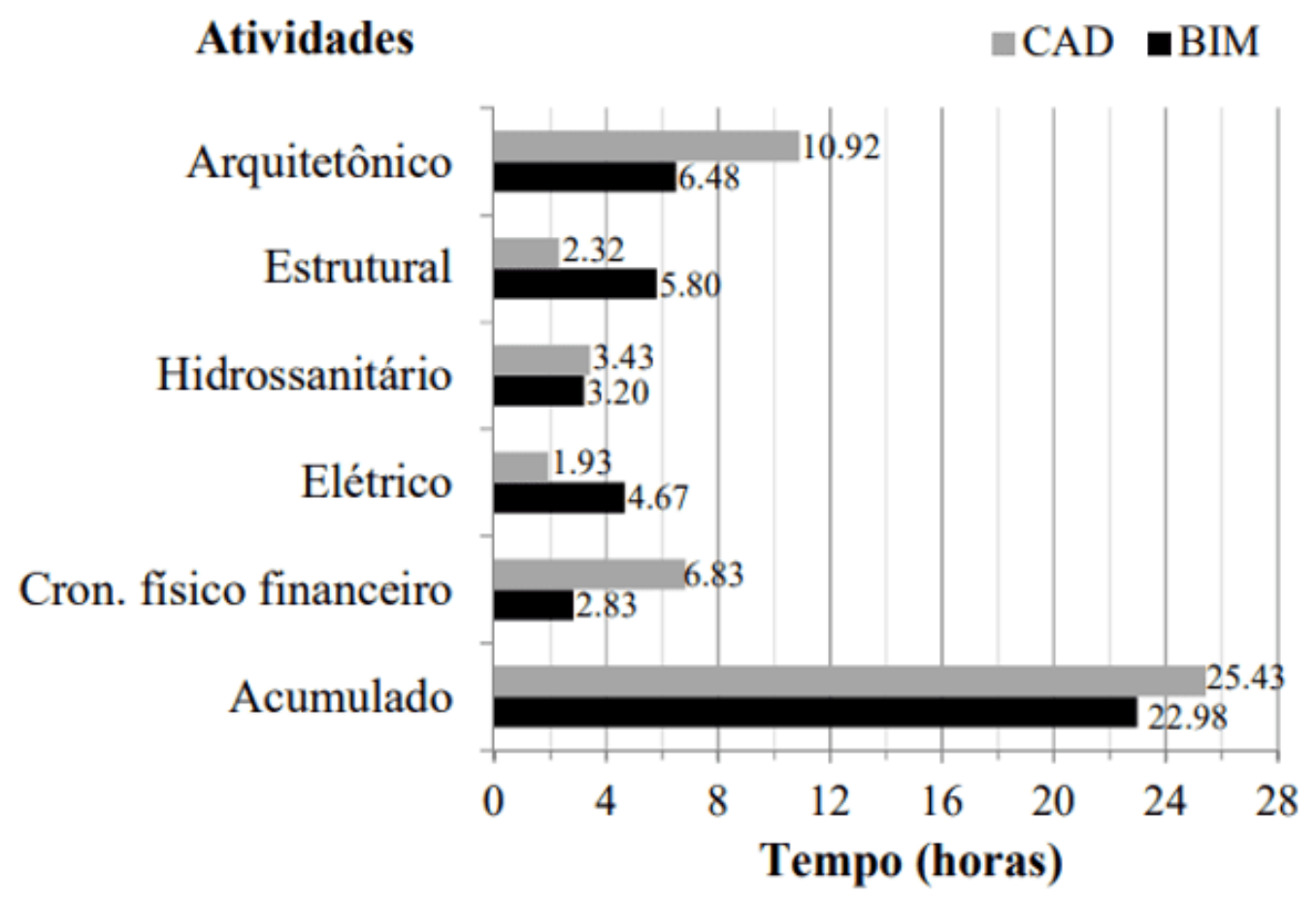

Fonte: NUNES; LEÃO, 2018, p. 47.

Segundo Nunes; Leão (2018, p. 47), o valor da hora técnica de projeto do engenheiro civil seguiu os valores estabelecidos pela ABENC, Associação Brasileira de Engenheiros Civis. Os valores em reais por metro quadrado foram determinados a partir da relação metro quadrado/hora de projeto.

Os honorários para a elaboração do projeto residencial, como nota-se na Figura 7, retrata o valor agregado por metro quadrado ao processo construtivo, logo, $20 \%$ das disciplinas correspondem ao cronograma físico financeiro. 
Figura 7: Honorários básicos para elaboração de projetos de edificações residenciais.

\begin{tabular}{cc}
\hline Projetos & Custo por metro quadrado $\left(\mathbf{R} \$ \mathbf{m}^{\mathbf{2}}\right)$ \\
\hline Arquitetônico & 35,09 \\
Estrutural & 11,57 \\
Hidrossanitário & 7,02 \\
Elétrico & 8,54 \\
Cronograma físico financeiro & $20 \%$ de todos os projetos \\
\hline
\end{tabular}

Fonte: NUNES; LEÃO, 2018, p. 47.

Enquanto alguns projetos realizados no AutoCad requerem pouco tempo para a elaboração, consomem mais financeiramente e, os realizados utilizando-se da tecnologia BIM, mesmo gastando mais tempo, nota-se uma economia. Com base na Figura 8 , o projeto hidrossanitário, por exemplo, com BIM levou-se mais tempo, gerando economia.

Figura 8 - Comparativo de remuneração horária para desenvolvimento dos projetos.

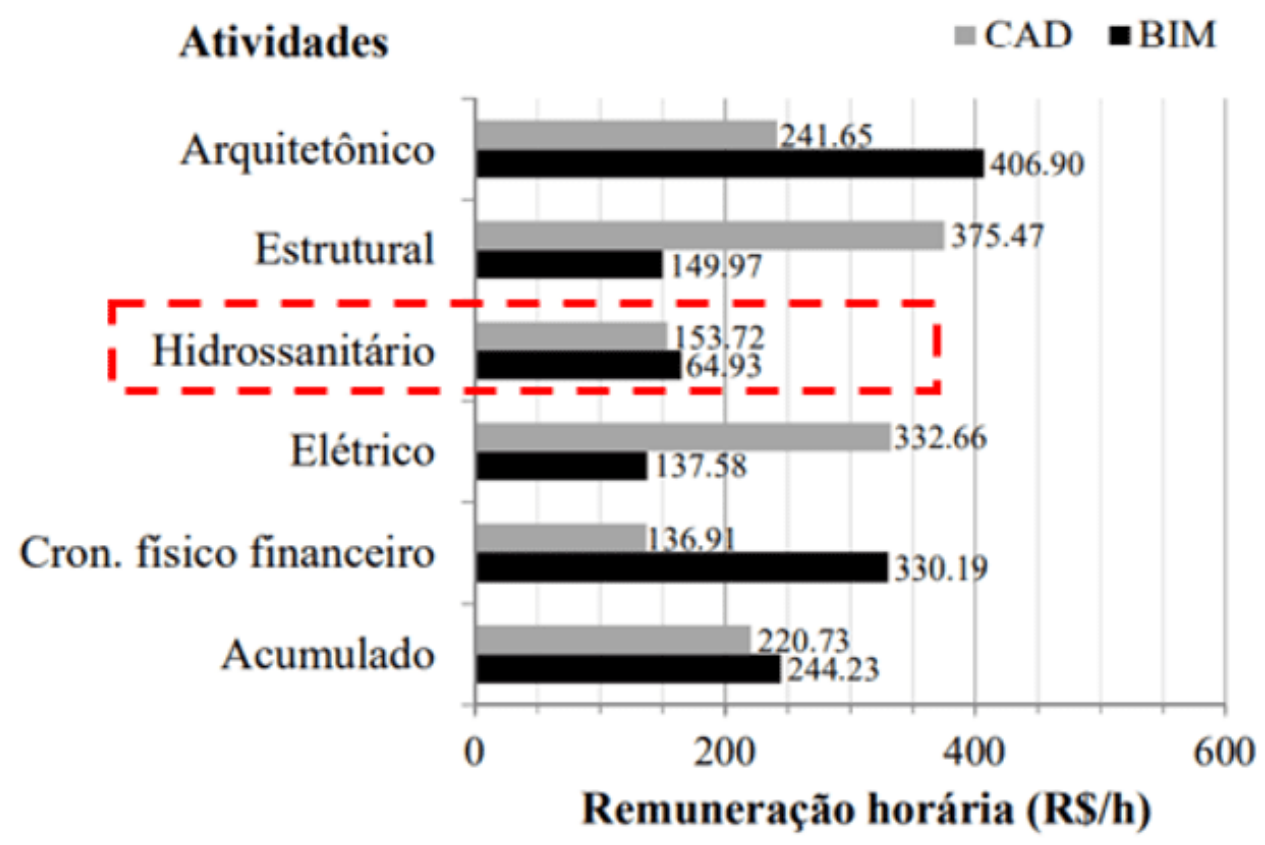

Fonte: NUNES; LEÃO, 2018, p. 47.

RC: 102547

Disponível em: https://www.nucleodoconhecimento.com.br/engenharia-civil/projetosde-engenharia 
Semelhantemente, a Figura 9 demostra o tempo gasto para o desenvolvimento das diretrizes de modelagem e etapas executivas do projeto arquitetônico. Nota-se que ao utilizar a tecnologia BIM, projetos em cortes, elevações e a representação tridimensional, não se aplicam ao montante de desenvolvimento, ou seja, a economia de quase $5 \%$ de tempo é fator positivo no desenvolvimento em BIM devido os padrões de modelagem já se iniciarem em 3D.

Figura 9 - Prazo de desenvolvimento do projeto arquitetônico.

\begin{tabular}{ccc}
\hline Arquitetônico & Metodologia CAD (h) & Metodologia BIM (h) \\
\hline Definições & 0,75 & 4,25 \\
Layout & 0,83 & 0,75 \\
Representação 3D & 2,33 & - \\
Projeto legal (implantação) & 0,53 & 0,43 \\
Projeto executivo (planta baixa, planta de cobertura) & 1,48 & 1,05 \\
Projeto executivo (cortes) & 4,20 & - \\
Projeto executivo (elevações) & 0,78 & - \\
Total & 10,92 & 6,48 \\
\hline
\end{tabular}

Fonte: NUNES; LEÃO, 2018, p. 47.

A necessidade do dimensionamento de pilares, vigas e lajes da edificação é dada em projeto e a maneira do detalhamento consolida toda a sustentação da obra. Como trata-se de um fator que contribui para a infraestrutura da construção, 0 conjunto de atividades em BIM mostra-se 3,48\% maior para a concepção estrutural, quando comparado ao sistema AutoCad, a Figura 10 ressalta a diferença entre o tempo gasto para a elaboração do projeto estrutural em BIM e AutoCAd. 
Figura 10 - Prazo de desenvolvimento do projeto estrutural.

\begin{tabular}{|c|c|c|}
\hline Estrutural & Metodologia CAD (h) & Metodologia BIM (h) \\
\hline Definições de software & 0,42 & 0,42 \\
\hline Preparação arquitetônico & 0,25 & 0,25 \\
\hline Lançamento da estrutura & 0,57 & 0,57 \\
\hline Dimensionamento & 0,07 & 0,07 \\
\hline $\begin{array}{c}\text { Análise estrutural (verificações) } \\
\text { 'Det-alhamento }-(\text { modelagem BIM) } \\
\text { 'Desenho executivo }\end{array}$ & $\begin{array}{l}0,33 \\
----\frac{2}{0,3}---- \\
0,37 \\
-----\end{array}$ & $---\frac{0,33}{3,80}-\overline{1}$ \\
\hline Total & 2,32 & 5,80 \\
\hline
\end{tabular}

Fonte: NUNES; LEÃO, 2018, p. 47.

Da mesma maneira, nota-se na Figura 11, que o prazo para a preparação do projeto hidrossanitário em BIM foi pouco menor comparado ao tempo de desenvolvimento no AutoCad, assim como teve a preparação arquitetônica desconsiderada devido a caracterização já tridimensional em BIM.

Figura 11 - Prazo de desenvolvimento do projeto hidrossanitário.

\begin{tabular}{ccc}
\hline Hidrossanitário & Metodologia CAD (h) & Metodologia BIM (h) \\
\hline Definições de software & 0,12 & 0,75 \\
Preparação arquitetônico & 0,47 & - \\
Lançamento da tubulação e conexões & 0,83 & 1,42 \\
Dimensionamento & 0,07 & 0,03 \\
Análise da tubulação (verificações) & 0,33 & 0,25 \\
Detalhamento das instalações & 0,20 & 0,50 \\
Desenho executivo & 1,42 & 0,25 \\
Total & 3,43 & 3,20 \\
\hline
\end{tabular}

Fonte: NUNES; LEÃO, 2018, p. 47.

$\mathrm{Na}$ elaboração do projeto elétrico, observa-se na Figura 12 que, para o dimensionamento do projeto proposto, o software Revit@ não atendeu a todas as necessidades do desenvolvimento, tal qual o tempo gasto para a elaboração foi quase $3 \%$ maior em BIM do que executado no AutoCad. 
Figura 12 - Prazo de desenvolvimento do projeto elétrico.

\begin{tabular}{ccc}
\hline Elétrico & Metodologia CAD (h) & Metodologia BIM (h) \\
\hline Definições de software & 0,25 & 0,58 \\
Preparação arquitetônico & 0,25 & 0,25 \\
Lançamento dos condutores e pontos elétricos & 0,42 & 0,35 \\
Dimensionamento & 0,17 & $*$ \\
Análise dos condutores & 0,38 & 0,22 \\
Detalhamento das instalações & 0,13 & 3,08 \\
Desenho executivo & 0,33 & 0,18 \\
Total & 1,93 & 4,67 \\
\hline
\end{tabular}

Nota: $\left({ }^{\star}\right)$ Entende-se que para a elaboração do projeto elétrico em BIM, o Revit® não supre todas as necessidades de dimensionamento. Fonte: NUNES; LEÃO, 2018, p. 47.

A Figura 13, apresenta o tempo demandado pelos sistemas AutoCad e BIM para preenchimento da planilha exigida pelo programa governamental para financiamento MCMV, hoje, Casa Verde e Amarela. O desenvolvimento da planilha pelo método BIM ocorre em 2/5 do tempo do método AutoCad, isso é reflexo dos dados não geométricos inseridos nas disciplinas anteriores (NUNES; LEÃO, 2018, p. 47).

Figura 13- Prazo de desenvolvimento do cronograma físico financeiro.

\begin{tabular}{ccc}
\hline Cronograma físico financeiro & Metodologia CAD (h) & Metodologia BIM (h) \\
\hline Planilha PFUI & 6,83 & 2,83 \\
\hline
\end{tabular}

Nota: Planilha PFUI, Proposta de Financiamento de Unidade Isolada, ferramenta usada para prestar contas à Caixa Econômica Federal. Fonte: NUNES; LEÃO, 2018, p. 47.

\section{FERRAMENTAS GENÉRICAS E BIM}

A tecnologia paramétrica que suporta a $B I M$, desempenha um papel importante no avanço do Design Generativo. A inteligência por trás das alternativas de multiplicação ou otimização de projeto é fornecida pelo algoritmo, então os 
diferentes valores básicos junto a um grupo de elementos de regras parametrizadas, fornecem resultados mais ágeis e inteligentes para o projeto.

O método de Design Generativo, teve início devido a retirada de dados pela manipulação de parâmetros e algoritmos, para combinações inteligentes de variáveis de modo a oferecer suporte a projetos, otimizando os processos até que se consiga o resultado desejado. O mecanismo não dispensa o próprio projetista, ao contrário, redireciona a maneira de trabalhar, atribuindo benefícios às ferramentas (MELLO, 2017).

Baseado em coordenação, interoperabilidade, reuso e compartilhamento de informações, estes sistemas modificam a continuidade dos projetos e implicam na mudança da estrutura da ação projetual, "com redefinição das estratégias de investigação, das técnicas e dos procedimentos de avaliação" (KOWALTOWSKI et al., 2011).

Os conceitos de Design Algorítmico, onde enfatiza o interesse às regras, instruções e fórmulas, assim como o Design Paramétrico, que determina os resultados gerando diversas alternativas ao projeto, se fundem aos valores do Design Generativo.

Parafraseando, para Mello (2017), esse sistema consiste em deixar computadores e inteligência artificial operarem um projeto, logo, observa-se o que é algoritmo paramétrico. O sistema predefine e organiza qualquer instrução graficamente.

De maneira geral, projetos generativos se caracterizam como a prática na qual o projetista usa um sistema com algum nível de autonomia, para produzir a solução para o problema de projeto (ABRISHAMI et al., 2014). Tais sistemas se caracterizam por uma mescla de definições abstratas de possíveis variações de projeto capazes de produzir um objeto (FISCHER; HERR, 2001). 


\section{DESAFIOS ENCONTRADOS}

A Agência Brasileira de Desenvolvimento Industrial em parceria com o Ministério da Indústria, Comércio Exterior e Serviços, já disponibilizaram a biblioteca pública BIM com centenas de elementos disponíveis para diversos softwares e conta com componentes construtivos discriminados por categoria, subcategoria, software e outras características que concedem o download mediante inscrição no próprio site da ABDI (ABDI, 2019).

Além dos modelos, a plataforma disponibiliza guias, normas e manuais relacionados ao sistema BIM e disponíveis gratuitamente para download. Igor Calvet, presidente da $A B D I$, ressalta que a capacitação também é um desafio e a equipe está empenhada na missão de encorajar a transformação digital na construção; um dos objetivos propostos pela Estratégia BIMBR, divulgada pelo Governo Federal (EQUIPE, 2020).

Outro importante fator de discussão citado por Rosso (2011, p. 61-64 apud MENEZES, 2011, p. 162), baseia-se na estimativa orçamentária de alguns softwares que compõem a plataforma, para àqueles que já aderiram, avalia-se como

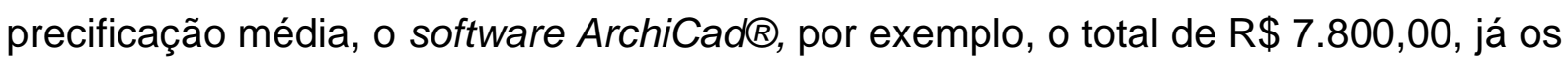

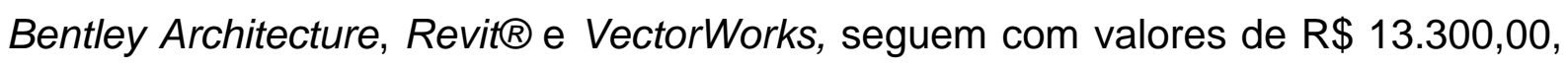
$\mathrm{R} \$ 10.000,00$ e $\mathrm{R} \$ 5.300,00$, respectivamente.

A Figura 14, lista alguns exemplos de softwares utilizados para a estruturação em $B I M$ para a criação dos projetos. Pode-se observar alguns programas que também oferecem uma extensão gratuita, como o Revit $\Theta$, da AutoDesk $\Theta$, que trabalha para o levantamento de quantidades, o NavisWorks $\AA$ da AutoDesk $\Theta$ e o TEKLA, que atuam na detecção de conflitos no desenvolvimento gradativo da modelagem. 
Figura 14: Softwares que interagem com BIM.

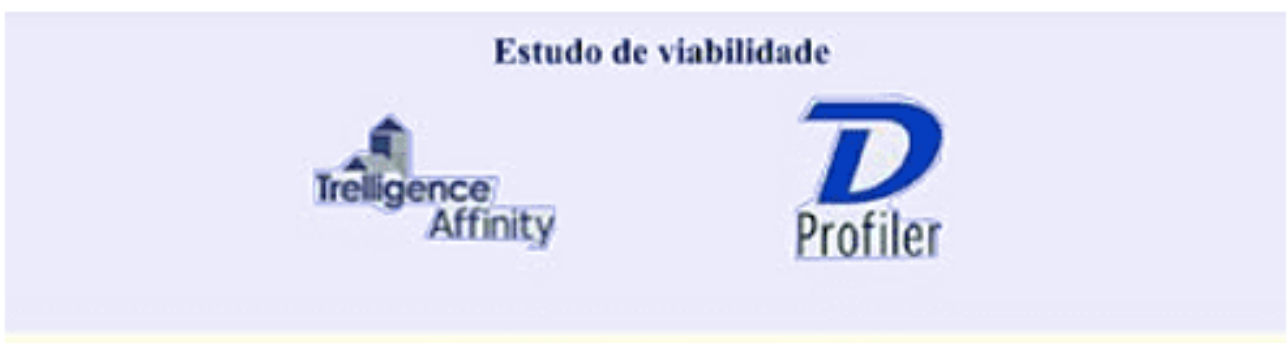

Levantamento de quantidades

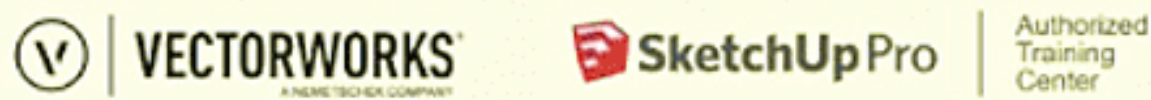
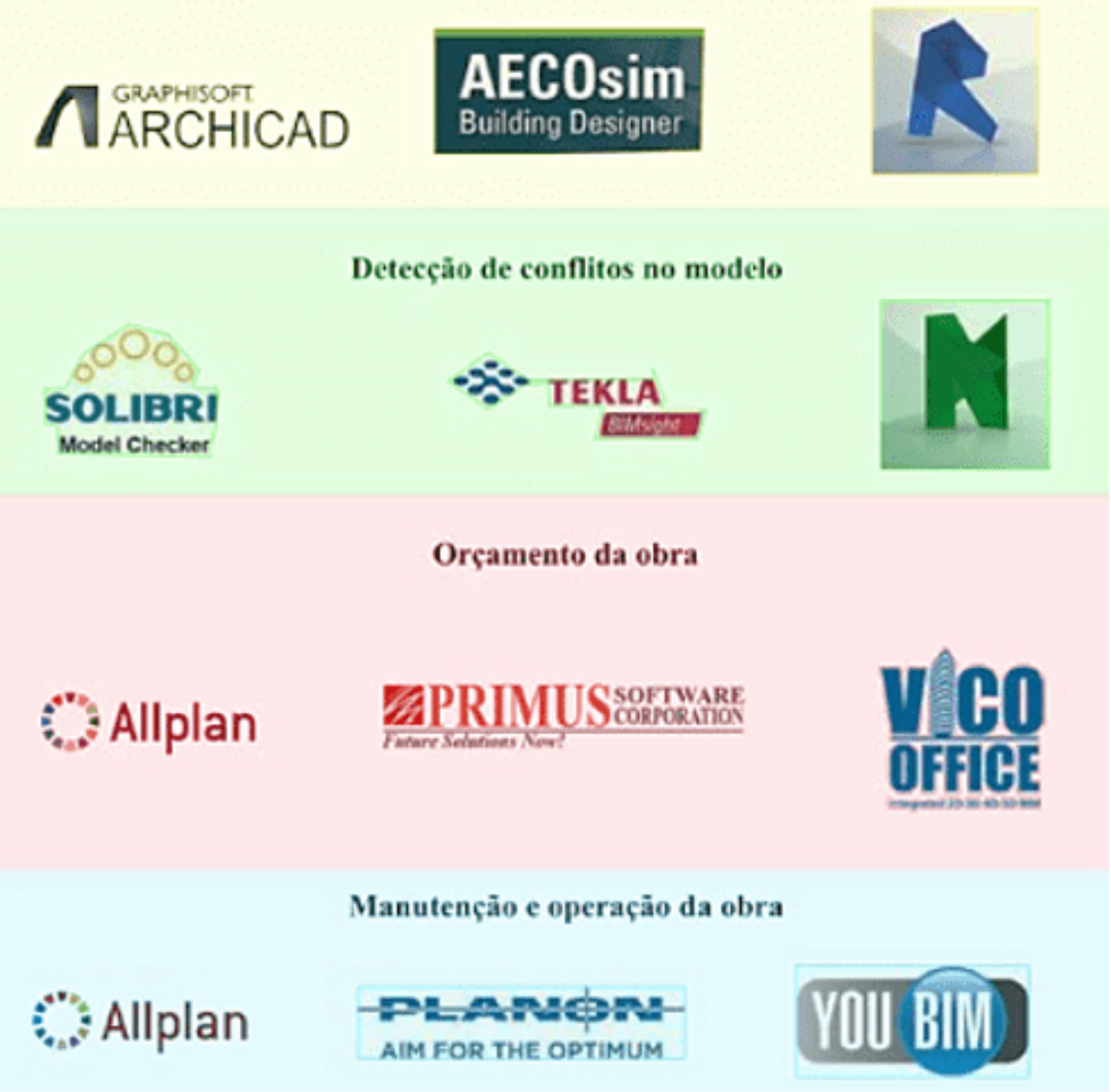

Fonte: MATTANA; LIBRELOTTO, 2017.

RC: 102547

Disponível em: https://www.nucleodoconhecimento.com.br/engenharia-civil/projetosde-engenharia 


\section{OPINIÕES ENTRE AUTORES}

Baseado em Eastman et al. (2014), as premissas rotineiras do uso em BIM, garantem derivar seções, planos, desenhos isométricos ou perspectivas com base em elementos modelados anteriormente a fim de evitar o redesenho, pois, todas as alterações são reportadas e atualizadas automaticamente de modo que a análise quantitativa e a descrição do material podem ser combinadas diretamente ao decorrer da modelagem.

A conexão e a fácil geração de estimativas de custos ou quantidades de materiais, além de fornecer uma base de dados integrada para geração de códigos automatizados, para fiscalização de prefeituras ou nos escritórios de Engenharia e Arquitetura, auxilia nas tarefas de grandes empreiteiras, em termos de vantagens de direitos de uso, como despacho e pedido materiais.

De acordo com Baroni (2011, p. 65-66, apud MENEZES, 2011, p. 160), algumas construtoras pediram a seus parceiros que desenvolvessem os projetos integralmente em BIM, embora esses casos ainda sejam minoria, no que diz respeito aos clientes, a tendência mundial já atinge o Brasil. Fato observado devido algumas empresas públicas, terem requerido a entrega dos projetos em BIM.

\section{CONSIDERAÇÕES ENTRE CONSTRUTORAS, ENGENHEIROS E ARQUITETOS}

No Brasil, segundo Beber (2010), a Construtora e pioneira na implantação de plataformas BIM, Gafisa, começou a desenvolver em 2010 cinco projetos residenciais para testar diferentes softwares para a plataforma, disponíveis no mercado, a empresa montou cinco equipes envolvendo funcionários da construtora, projetistas terceirizados e consultores, uma para cada empreendimento.

Com o software Revit ${ }^{\circ}$, foram projetados um empreendimento em Brasília e um em Goiânia; com a ferramenta da Bentley, um imóvel em Santos; com o VectorWorks, 
um em São José dos Campos e com o ArchiCAD, outro prédio em Goiânia. Beber (2010), ainda cita que a iniciativa foi apresentada pelo gerente de projetos da Gafisa, Ewerton Bonetti, durante o Seminário BIM, promovido pelo Sinduscon-SP - Sindicato da Indústria da Construção Civil do Estado de São Paulo.

Fábio Nakayama, Engenheiro Coordenador de projetos da Soeng Construção Hidroelétrica e especializado em obras e instalações, relata que hoje existem requisitos de Arquitetos e construtores, exigindo os projetos em BIM e declarou:

Se nos últimos anos a Soeng rejeitou algumas propostas, agora está trabalhando com a Gafisa para desenvolver um projeto piloto, que nasceu originalmente em $C A D$ e posteriormente modelado inteiramente em BIM"'. (SAYEGH, 2011, p. 72-75, apud MENEZES, 2011, p. 165).

Considerando Gerolla (2011, p. 16-17 apud MENEZES 2011, p. 166), o discurso de Cervantes Ayres, Arquiteto, diretor-geral da Secretaria de Urbanismo de São José dos Pinhais, Paraná, que está implantando BIM, as dificuldades se concentram nas barreiras técnicas, econômicas, jurídicas e educacionais que prejudicam seu uso nos modelos de produção da construção.

De acordo com Gerolla (2011, p. 16), Ayres acredita que, a adoção de tecnologia é progressivamente mais necessária e a transição para BIM deve ser iniciada o mais rápido possível, caso contrário as empresas estrangeiras ganharão cada vez mais espaço no Brasil, impulsionadas pela baixa quantidade de engenharia no mercado brasileiro (apud MENEZES 2011, p. 166).

\section{CONSIDERAÇÕES FINAIS}

O presente artigo visou responder: Como será realizada a implantação do Building Information Modeling para elaboração dos projetos de engenharia do Sistema Federal Brasileiro? Diante do exposto, foi possível constatar que a implantação da BIM para a execução de projetos de engenharia do Sistema Federal Brasileiro, tem 
acontecido de forma escalonada, a fim de proporcionar tempo de adaptação ao mercado.

Os projetos públicos de engenharia e arquitetura, assim como o de instalações elétricas, hidráulicas e sistemas de refrigeração e aquecimento que se iniciaram em janeiro de 2021, já fazem uso da tecnologia BIM.

Em continuidade às regras de implantação, a partir do ano de 2024, serão incluídos aos projetos, todo o planejamento orçamentário da construção, assim como as built, atualizações feitas no decorrer da obra. Por fim, no ano de 2028, os processos de gestão da obra e manutenção, serão adicionados às etapas de obrigatoriedade para a criação de novas construções e projetos de reformas. A adoção da tecnologia BIM, contribuirá para o aumento de sustentabilidade, rapidez nas obras e redução de gastos em todo o processo construtivo.

Entende-se que a $B I M$, acompanha o progresso no processo de virtualização de projetos, atingindo as dimensões $8 \mathrm{D}$, a introdução da segurança do trabalho para os processos construtivos.

O uso da modelagem em BIM ao ser comparado com a modelagem em Cad, na execução de um projeto popular do programa Casa Verde Amarela, agrega uma economia de $11 \%$ do orçamento total da obra, poupa 5 horas de trabalho de modelagem e reduz em 4 horas o tempo de preenchimento da planilha de prestação de contas disponibilizada pela Caixa Econômica Federal, documento obrigatório para o financiamento de casas, hoje em dia, o tempo médio para o cadastro da planilha, equivale a 6 horas diárias.

Especula-se que o lucro gerado ao PIB da Construção no Brasil, pode ser ainda maior com o uso da BIM para a realização de projetos de obras públicas, devido ao tempo economizado no método de criação, cada vez mais projetos serão realizados em menos tempo, agregando movimentação financeira ao país. 
Conclui-se que para diversos profissionais da área e escritores, a BIM garante o fim do redesenho, pois qualquer modificação ao projeto é reportada automaticamente à plataforma, oferecendo atividades ainda mais automatizadas e livres de falhas.

Ao decorrer dos processos de mudanças, estima-se que ainda mais ferramentas genéricas cooperem para a evolução em BIM e seus processos parametrizados, como por exemplo, os projetos generativos, que junto às diversas regras parametrizadas, fornecem resultados mais ágeis e inteligentes ao projeto de maneira totalmente virtual e sistematizada através da manipulação de algoritmos. O processo é benéfico à evolução, pois reestrutura os parâmetros projetuais e a maneira de se operar.

\section{REFERÊNCIAS}

ABDI. Construção Civil mais inteligente, produtiva e econômica. In: Construção Civil mais inteligente, produtiva e econômica. [S. I.], 2019. Disponível em: https://www.abdi.com.br/projetos/bim. Acesso em: 4 set. 2021.

ABNT (Brasil). ISO 12006-2:2010. Sistema de classificação da informação da construção: Parte 1: Terminologia e estrutura, [S. I.]: ABNT - Associação Brasileira de Normas Técnicas, p. 6, 14 jul. 2011. Disponível em: https://www.abntcatalogo.com.br/norma.aspx?Q=ED98BA3EB6A47DABA73AEC820 91E878F871EF5F24B23CCB3C618F3FD4C5FFD89. Acesso em: 4 set. 2021.

ABNT (Brasil). ISO 12006-2:2015. Organização de informação da construção: Parte 2: Estrutura para classificação, [S. I.]: ABNT - Associação Brasileira de Normas Técnicas, p. 26, 27 fev. 2018. Disponível em: https://www.abntcatalogo.com.br/norma.aspx?Q=C88173960913AA69CA01C1F907 23A6553EA27A4807ECF5E37DCAB6FE697666A5. Acesso em: 4 set. 2021.

ABRISHAMI, Sepehr; GOULDING, Jack Steven; RAHIMIAN, Farzad Pour; GANAH, Abdulkadir. Integração de BIM e design generativo para explorar a inovação de design conceitual AEC: Status Atual e Tendências Futuras. Jornal de Tecnologia 
da Informação na Construção ITcon, [S. I.], v. 19, p. 350-359, 21 set. 2014. Disponível em: https://www.itcon.org/paper/2014/21. Acesso em: 2 out. 2021.

\section{BAIA, Denise Valéria Santos. USO DE FERRAMENTAS BIM PARA O} PLANEJAMENTO DE OBRAS DA CONSTRUÇÃO CIVIL. Orientador: Antônio Carlos Oliveira Miranda. 2015. 107 f. Dissertação (Mestrado Em Estruturas E Construção Civil) - Faculdade De Tecnologia Universidade De Brasília, 2015. Disponível em: https://repositorio.unb.br/bitstream/10482/22996/1/2015_DenizeVal\%c3\%a9riaSanto sBaia.pdf. Acesso em: 5 set. 2021.

BEBER, Michelle. GAFISA TESTA QUATRO SOFTWARES BIM. In: Arquitetura I Construção. [S. $\quad$ I.], 15 dez. 2010. Disponível em: https://incorporacaoimobiliaria.com/2010/12/16/gafisa-testa-quatro-softwares-bim/. Acesso em: 5 set. 2021.

BRASIL. Lei no 14.133, de 10 de janeiro de 2002. Lei de Licitações e Contratos Administrativos. Diário Oficial da União: Seção: 1 - Extra F - Edição 61-F, Brasília, DF, n. 61, p. 2, 1 abr. 2021. Disponível em: https://www.in.gov.br/en/web/dou/-/lei-n14.133-de-1-de-abril-de-2021-311876884. Acesso em: 5 set. 2021.

BRASIL. Lei $n^{\circ}$ 10.406, de 10 de janeiro de 2002. Institui o Building Information Modelling. Diário Oficial da União: Seção 1, Brasília, DF, n. 65, p. 5-7, 2 abr. 2020. Disponível em: https://pesquisa.in.gov.br/imprensa/jsp/visualiza/index.jsp?data=03/04/2020\&jornal=5 15\&pagina=5\&totalArquivos=146. Acesso em: 5 set. 2021.

CBIC (Brasília - DF). Informativo Econômico: Construção Civil mostra resiliência e cresce 2,7\% no $2^{\circ}$ trimestre/21. In: Informativo Econômico: Construção Civil mostra resiliência e cresce $2,7 \%$ no $2^{\circ}$ trimestre/21. [S. I.], 1 set. 2021. Disponível em: https://cbic.org.br/wp-content/uploads/2021/09/informativo-economico-pib-2otrimestre-2021-final-final.pdf. Acesso em: 10 set. 2021. 
CBIC (Brasília - DF). Informativo Econômico: Resultados do PIB Brasil e da Construção no $1^{\circ}$ trimestre surpreendem. In: Informativo Econômico: Resultados do PIB Brasil e da Construção no $1^{0}$ trimestre surpreendem. [S. I.], 1 jun. 2021. Disponível em: https://cbic.org.br/wp-content/uploads/2021/06/informativoeconomico-pib-10-trim-2021.pdf. Acesso em: 10 set. 2021.

CBIC (Brasília - DF). PIB nacional cresce 1,1\% em 2018, mas setor da construção encolhe pelo quinto ano consecutivo. In: PIB nacional cresce 1,1\% em 2018, mas setor da construção encolhe pelo quinto ano consecutivo. [S. I.], 28 fev. 2019. Disponível em: https://cbic.org.br/es_ES/33505-2/. Acesso em: 10 set. 2021.

CHEBATT, Thais Fernandes. Building Information Modeling - BIM: evolução em projetos de construção e infraestrutura no Brasil. In: MIGALHAS. Building Information Modeling - BIM: evolução em projetos de construção e infraestrutura no Brasil. [S. I.], 17 maio 2021. Disponível em: https://www.migalhas.com.br/depeso/345600/building-information-modeling--bim. Acesso em: 5 set. 2021.

COBENGE, XL., 2012, Belém - PA. ESTUDO COMPARATIVO DE FERRAMENTAS COMPUTACIONAIS QUE UTILIZAM TECNOLOGIA BIM PARA DESENVOLVIMENTO DE PROJETOS DE ENGENHARIA CIVIL [...]. [S. I.: s. n.], 2012. 12 p. Disponível em: https://www.mackenzie.br/fileadmin/OLD/62/ARQUIVOS/PUBLIC/user_upload/_impo rted/fileadmin/LABGEO/Trabalhos/2012/COBENGE_-

_Estudo_comparativo_de_ferramentas_computacionais_que_utilizam_tecnologia_bi m_para_desenvolvimento_de_projetos_de_engenharia_civil.pdf. Acesso em: 5 out. 2021.

COSTA, Carlos; OLIVEIRA, David Paulo R de; FOGLI, Matheus de Souza; BENFICA, Sandra Schaaf; MACIEL, Alex Roda; MARCELLINI, Laura; MANZIONE, Leonardo; KRIPPAHL, Miguel; ONEDA, Gian Felippe Lisboa; CAMERINI, Luana 
Moreira; MOREIRA, Rogério da Silva; SCHEER, Sergio; SALGADO, Monica Santos. Guia 1 - O Processo de Projeto BIM: Coletânea Guias BIM ABDI-MDIC. In: GUIA 1 - O Processo de Projeto BIM: Coletânea Guias BIM ABDI-MDIC. Brasília - DF: [s. n.], 2017. v. 1, p. 1-82. ISBN 978-85-61323-43-1. Disponível em: https://mutual.com.br/wp-content/uploads/2018/01/GUIA-BIM01_20171101_web.pdf. Acesso em: 10 set. 2021.

EASTMAN, Chuck et al. Manual de BIM: um guia de modelagem da informação da construção para arquitetos, engenheiros, gerentes, construtores e incorporadores. Tradução de Cervantes Gonçalves Ayres Filho et al. Porto Alegre: Bookman Editora Ltda, 2014. 503 p. ISBN 978-85-8260-118-1.

EQUIPE (Brasil). ArchDaily. ABDI lança curso online e gratuito de BIM. In: EQUIPE (Brasil). ArchDaily (ed.). ABDI lança curso online e gratuito de BIM. ISSN 07198906. ed. [S. I.], 10 nov. 2020. Disponível em: https://www.archdaily.com.br/br/950925/abdi-lanca-curso-online-e-gratuito-debim?ad_source=search\&ad_medium=projects_tab\&ad_source=search\&ad_medium= search_result_all. Acesso em: 2 out. 2021.

FISCHER, Thomas; HERR, Christiane M. Teaching Generative Design. Teaching Generative Design, [s. l.], p. 1-14, 2001. Disponível em: http://www.generativeart.com/on/cic/ga2001_PDF/fischer.pdf. Acesso em: 15 set. 2021.

INBEC (Fortaleza - CE). Uso do BIM será obrigatório a partir de 2021 nos projetos e construções brasileiras. In: INBEC (Fortaleza - CE). Uso do BIM será obrigatório a partir de 2021 nos projetos e construções brasileiras. [S. I.], 25 jan. 2020. Disponível em: https://inbec.com.br/blog/uso-bim-sera-obrigatorio-partir-2021projetos-construcoes-brasileiras. Acesso em: 10 out. 2021.

KOWALTOWSKI, Doris C. C. K.; MOREIRA, Daniel de Carvalho; PETRECHE, João R. D.; FABRíCIO, Márcio M. O Processo de Projeto em Arquitetura: da Teoria à 
Tecnologia. 1. ed. [S. I.]: Oficina de Textos, 2011. 504 p. ISBN 8579750334; 9788579750335 .

MATTANA, Leticia; LIBRELOTTO, Lisiane Ilha. CONTRIBUIÇÃO DO BIM PARA A SUSTENTABILIDADE ECONÔMICA DE EDIFICAÇÕES. Mix Sustentável (edição especial - V ENSUS), [s. l.], v. 3, n. 2, 2017. Disponível em: https://mixsustentavel.paginas.ufsc.br/files/2017/05/Mix-Sustent\%C3\%A1vel-6Artigo-15.pdf. Acesso em: 10 out. 2021.

MELLO, Ricardo Bianca. Mundo AEC - Blog Oficial sobre AEC da Autodesk Brasil. In: MELLO, Ricardo Bianca. Do Projeto Paramétrico ao Projeto Generativo: Parte 1: O que é projeto generativo. [S. I.], 19 jan. 2017. Especialista Técnico da Autodesk para Arquitetura, Engenharia e Construção. Disponível em: https://blogs.autodesk.com/mundoaec/projeto-generativo-parte-1/. Acesso em: 2 out. 2021.

MELLO, Ricardo Bianca. Mundo AEC - Blog Oficial sobre AEC da Autodesk Brasil. In: MELLO, Ricardo Bianca. Do Projeto Paramétrico ao Projeto Generativo: Parte 2: Projeto Algorítmico e Dynamo (com apostila). [S. I.], 2 fev. 2017. Especialista Técnico da Autodesk para Arquitetura, Engenharia e Construção. Disponível em: https://blogs.autodesk.com/mundoaec/projeto-generativo-parte-2/. Acesso em: 2 out. 2021.

MENEZES, Gilda Lúcia Bakker Batista de. Breve histórico de implantação da plataforma BIM. Cadernos de Arquitetura e Urbanismo, [s. I.], ano 2011, v. 18, ed. 22, p. 153-171, 2011. Disponível em: file://C:/Users/ALMEE/Downloads/3363Texto\%20do\%20artigo-13698-1-10-20120516\%20(1).pdf. Acesso em: 5 set. 2021.

NUNES, Gustavo Henrique; LEÃO, M. Estudo comparativo de ferramentas de projetos entre o CAD tradicional e a modelagem BIM. Estudo comparativo de ferramentas de projetos entre o CAD tradicional e a modelagem BIM, [s. I.], ed. 55 ,

p.

47-61, 2018.

Disponível

em: 
https://www.civil.uminho.pt/revista/artigos/n55/Pag.47-61.pdf. Acesso em: 11 out. 2021.

SIENGE. TECNOLOGIA BIM: Guia Completo. In: SIENGE. TECNOLOGIA BIM: Guia Completo. [S. I.], 2021. Disponível em: https://www.sienge.com.br/guiacompleto-sobre-tecnologia-bim/. Acesso em: 10 set. 2021.

THOMÉ, Brenda Bressan. O que é BIM?: Entenda agora o conceito e suas aplicações. In: SIENGE. $O$ que é BIM?: Entenda agora 0 conceito e suas aplicações. [S. I.], 8 set. 2016. Disponível em: https://www.sienge.com.br/blog/vocesabe-o-que-e-bim-entenda-o-conceito-e-suas-aplicacoes/. Acesso em: 5 nov. 2021.

THÓRUS. Tudo sobre BIM: o que é, ferramentas e por onde começar [2020]. In: THÓRUS ENGENHARIA. Tudo sobre BIM: o que é, ferramentas e por onde começar [2020]. Joinville - SC, 22 maio 2020. Disponível em: https://thorusengenharia.com.br/o-que-e-bim/. Acesso em: 15 out. 2021.

Enviado: Julho, 2021.

Aprovado: Dezembro, 2021. 